\title{
Exploring the Impact of ICT in CPFR: A Case Study of an APS System in a Norwegian Pharmacy Supply Chain
}

\author{
Maria Kollberg Thomassen ${ }^{1, *}$, Heidi Dreyer ${ }^{2}$, and Patrik Jonsson ${ }^{3}$ \\ ${ }^{1}$ SINTEF Technology and Society, Industrial Management, Trondheim, Norway \\ maria.thomassenesintef.no \\ ${ }^{2}$ The Norwegian University of Science and Technology, \\ Dept. of Production and Quality Engineering, Trondheim, Norway \\ heidi.dreyer@ntnu.no \\ ${ }^{3}$ Chalmers University, Dept. of Technology Management and Economics, Gothenburg, Sweden \\ patrik.jonsson@chalmers.se
}

\begin{abstract}
This study aims at exploring how ICT affects CPFR with focus on information flows in planning and control processes. A case study of a pharmacy supply chain in Norway is conducted to investigate process changes related to an APS system implemented to support a CPFR initiative. Process changes are investigated in view of enhanced information, automated processes and organizational transformation. This study shows that the main impact of ICT is associated with enhanced information flows and transformed processes that its contribution to reducing labour is more limited, and that large information volumes are critical. Adding to current CPFR literature this work provides insights to the contribution of ICT with focus on enhanced information and process transformation. The importance of automatic features of ICT in information processing and exchange and its contribution to improved planning and control information as well as to implementing a joint CPFR approach is especially highlighted.
\end{abstract}

Keywords: ICT, CPFR, supply chain collaboration, planning and control.

\section{Introduction}

Planning and control of demand and supply involves a wide range of decisions spanning from long term strategic to more short term operational perspectives, including for instance inventory location, production capacity scheduling, shop floor execution, demand planning, distribution planning and network planning (Vollmann et al., 2005). Along with the supply chain management concept, suggesting that business competition takes place between supply chains rather than individual companies (Mentzer et al., 2001), joint planning and control approaches for matching demand and supply in the supply chain, have emerged (Stadtler \& Kilger, 2008). A wide range of concepts for collaboration between supply chain partners, on planning and control, have emerged during the last decades. These concepts can take different forms in

\footnotetext{
* Corresponding author.

C. Emmanouilidis, M. Taisch, D. Kiritsis (Eds.): APMS 2012, Part II, IFIP AICT 398, pp. 120-127, 2013.

(C) IFIP International Federation for Information Processing 2013
} 
practice and include for instance quick response $(\mathrm{QR})$, efficient consumer response (ECR), vendor managed inventory (VMI) and collaborative planning, forecasting and replenishment (CPFR).

CPFR offers a general approach to collaboration between partners and may be adopted in a wide array of variants (Skjøtt-Larsen et al., 2003). CPFR emerged in the US in the mid 1990s and the Voluntary Interindustry Commerce Solutions (VICS) Association published its first CPFR voluntary guidelines in 1998, the consumer packaged goods industry being the primary target group (Seifert, 2003, Ireland \& Crum, 2005). Despite a wide range of CPFR pilots implementations, several studies show that adoption has been slow in practice and large-scale implementations have been scarce (Barratt, 2004b, Olhager \& Selldin, 2004, Seifert, 2003).

Recent developments in new technologies for storing, exchanging, processing and communicating information i.e. information and communications technology (ICT), have offered numerous opportunities to handle information within and between companies. Enterprise resource planning (ERP) systems have traditionally been adopted to support planning and control of operations within companies. However, CPFR may be supported also by other types of ICT applications including for instance automated replenishment systems, advanced planning and scheduling (APS) systems, collaborative software and electronic data interchange (EDI).

Considering the increasing interest for CPFR and that it is closely related to the use of technology, it is surprising that only a handful empirical studies have been identified that focus on ICT adoption. Moreover, CPFR initiatives may be realized without ICT, but ICT can also imply the realization of considerable potential benefits. Even though several successful CPFR pilots with ICT support have been reported on (ECR Europe, 2002), studies providing detailed insights to ICT benefits are scarce. Literature highlights for instance that ICT is important to increase efficiency (Smith, 2006, Cederlund et al., 2007), especially when dealing with large volumes of information (Barratt, 2004a) and that ICT may enhance scalability and level of detail in collaboration (Ireland \& Crum, 2005).

Effects of adopting ICT in CPFR and other forms of collaboration are recognized in literature. Nevertheless, limited empirical evidence is presented to help draw strong conclusions about the consequences of technology. These need to be more systematically investigated in order to bring further structure to the wide range of effects that ICT may cause in CPFR settings, i.e. how ICT contributes to enriched information, automated processes and organizational transformation, for instance. Adopting a structured and comprehensive approach, several different dimensions of the impact of ICT may be taken into consideration in a systematic way.

The purpose of this paper is to explore how ICT affects CPFR with focus on information flows in planning and control processes. The empirical setting consists of a CPFR initiative established between a pharmacy retailer and a wholesaler in Norway. This work is expected to contribute to highlighting elements and aspects that are critical to how ICT affects CPFR. 


\section{Theoretical Background}

\subsection{Processes and Information Flows in CPFR}

The CPFR framework by the VICS Association is used to define key processes and information flows (VICS Association 2004, 2002, ECR Europe, 2001, 2002). In brief, CPFR encompasses four main processes;

- Planning and strategy includes the collaboration agreement and joint business planning activities. It establishes the basic rules for the collaboration, develops event plans and defines product mix and placement.

- Demand and supply management includes the sales forecasting and order planning/forecasting activities, in order to projects consumer demand.

- Execution encompasses order generation and fulfilment and includes the administrative tasks related to placing orders and the physical order fulfilment tasks such as preparation and delivery of shipments, reception and stocking of products on retail shelves, record of sales transactions and payments.

- Analysis involves exception management and performance assessment, aggregating results of key performance metrics, sharing insights and adjusting plans for continuous improvements.

Because the responsibility of collaborative activities is often distributed between partners and activities depend upon input information from both customers and suppliers, information is often exchanged between partners. The exchange of information is considered to be necessary to establish joint plans and forecast to be used for generating replenishment orders. The key information types of CPFR are:

- Collaboration arrangement: defines overall guidelines, rules, goals and scope of collaboration, mission statement, roles and responsibilities and performance measurement.

- Business plan: defines overall strategies and tactics for replenishment items comprising promotions, inventory policy changes, store openings and closings, production introductions, category and promotional plans and item management profile.

- Sales forecast: a projection of future sales for a given time period and location.

- Order forecast: a forecast of anticipated orders.

- Order: defines quantities of items to be delivered to a specific location.

- Execution information: execution data of current events and results of order fulfilment.

Since the collaboration arrangement and business plan are established on a long-term basis and are primarily based upon joint discussions and negotiations, information exchange mainly takes place during meetings. Since more frequent activities including sales forecasting and order forecasting are often led by one partner but depend upon information input from both partners, the use of ICT for communicating information is especially relevant. 


\subsection{ICT and Process Changes}

The framework by Mooney, et al. (1996) is used to structure identified process changes, Table 1. The framework is based upon three categories reflecting three different perspectives on the impact of ICT, including the automational, informational and transformational changes.

Table 1. Process changes categories

\begin{tabular}{l|ll}
\hline Category & Definition & Examples of performance metrics \\
\hline Automational & $\begin{array}{l}\text { Process changes related to the } \\
\text { use of ICT as a means for } \\
\text { directly substituting labour. }\end{array}$ & $\begin{array}{l}\text { Employee productivity, information } \\
\text { processing cost, cost of goods sold, utili- } \\
\text { zation of resources, total supply chain } \\
\text { management costs }\end{array}$ \\
Informational & $\begin{array}{l}\text { Process changes related to the } \\
\text { use of ICT for facilitating the } \\
\text { use of information. }\end{array}$ & $\begin{array}{l}\text { Delivery performance, product quality, } \\
\text { information quality, inventory perform- } \\
\text { ance }\end{array}$ \\
$\begin{array}{l}\text { Process changes related to the } \\
\text { use of ICT for facilitating and } \\
\text { supporting process innova- } \\
\text { tion and transformation. }\end{array}$ & $\begin{array}{l}\text { Delivery flexibility and frequency, prod- } \\
\text { uct flexibility, responsiveness to urgent } \\
\text { deliveries, range of inventory and prod- } \\
\text { ucts, cycle times, response times and lead } \\
\text { times }\end{array}$ \\
\hline
\end{tabular}

The automational category reflects the efficiency perspective of value deriving from ICT replacing labour. The use of ICT for eliminating human labour may be directly associated with mechanization of current ways of doing business, leaving existing processes intact.

The informational perspective reflects the use of ICT to collect, store, process and disseminate information to support decision making and enhance product quality. It also reflects the use of ICT to develop new intellectual skills and to enhance the use of information about process performance for purposes of understanding, closely monitoring of process status and objects, analysing information and decision-making.

The transformational view refers to the use of ICT to facilitate and support process innovation and transformation including re-engineering of processes and redesign of organizational structures.

\section{Research Approach}

A case study approach was adopted in this research. Empirical data was collected from a supply chain consisting of a wholesaler and a retailer in the Norwegian pharmacy industry. This industry has undergone major transformations since the new pharmacy law came into force in 2001. New competitive requirements with regard to sales and distribution have thus opened for new collaboration opportunities between wholesalers and retailers. The requirements on the logistics system in the pharmacy 
industry are similar to those of other retailing and FMCG industries, characterized by short lead times, high efficiency and high service levels

The investigation focused on the impact of ICT, especially an APS system that was implemented in 2006 to support a joint CPFR initiative between two companies that were part of the same company group.

This initiative was initiated to facilitate the replenishment of goods from the warehouse to 145 pharmacies in Norway. The empirical data were principally collected by semi-structured face-to-face interviews; a total of 18 interviews were conducted with employees representing the wholesaler, the retailer chain administration, the pharmacies, the joint management team and the joint replenishment team.

The analysis of empirical material is based on a comparison of CPFR processes before and after the APS system was implemented. This before-after comparison permitted the identification of process changes. In order to capture both before and after perspectives, interviewees were selected who had in-depth insights to how processes were carried out after the APS system implementation as well as before. Due to that the situation before the system implementation was investigated in a retrospective perspective, a larger amount of empirical data were related to after the system implementation compared to before.

\section{$4 \quad$ Findings}

Before the APS system was implemented, the retailer and the wholesaler collaborated primarily on long term planning. Planograms and other relevant market directives used to be transferred to the pharmacies from the pharmacy chain administration that was responsible for planning of market activities and sales forecasting. Pharmacies were responsible for deciding order quantities and timing, for generating orders locally and sending them to the wholesaler.

The new CPFR initiative implied that a joint planning and control approach was adopted and integrated in the APS system for replenishment of pharmacy inventories. A joint replenishment team was established with responsibility for the new APS system, ensuring centralized replenishment. The system enabled automatic demand forecasting and order generation with exception management. The control of planograms, campaigns, phasing in/out of items was also integrated in the new planning and control approach and the APS system supported daily and automatic update of assortment changes information in pharmacies. The information stored in the APS database was further used for detailed analysis and follow-up on performance.

Several major changes were identified by comparing processes before and after the APS system implementation, see Table 2. The majority of changes were concentrated to three principal activities; order planning/forecasting, order generation and performance assessment. The system helped to reduce the need for labour in pharmacies; time savings on ordering corresponded to 0.5 FTE per pharmacy. However, the main contribution of the system was related to its informational impact, by improving the accuracy in orders and order forecasts and the facilitation of the implementation of a 
common planning and control approach for pharmacy inventories. This led to major reductions in pharmacy inventory. Because the APS system was tightly integrated with the collaborative planning and control approach of the CPFR initiative, it facilitated the centralization of order planning/forecasting, order generation and performance assessment. Also, it improved the collaborative conditions in the CPFR initiative, by formalising, structuring and standardizing information flows and routines.

Table 2. Key process changes identified

\begin{tabular}{|c|c|c|}
\hline Category & Key process changes & \\
\hline $\begin{array}{l}\text { Automa- } \\
\text { tional }\end{array}$ & Time savings in pharmacies & \\
\hline $\begin{array}{l}\text { Informa- } \\
\text { tional }\end{array}$ & $\begin{array}{l}\text { New competence requirements } \\
\text { Automatic update of assortment } \\
\text { changes } \\
\text { More standardized and varied assort- } \\
\text { ment } \\
\text { More formalized and standardized } \\
\text { implementation of market plans } \\
\text { Improved pharmacy inventory per- } \\
\text { formance } \\
\text { More planning flexibility and stan- } \\
\text { dardization } \\
\text { Customized campaigns } \\
\text { Higher forecast accuracy }\end{array}$ & $\begin{array}{l}\text { Centralized and automatic order } \\
\text { generation } \\
\text { Automatic update of POS data and } \\
\text { inventory levels } \\
\text { Higher order accuracy } \\
\text { Combined costs of pharmacies and } \\
\text { warehouse in order calculations } \\
\text { Reduced costs in warehouse } \\
\text { Automatic exceptions management } \\
\text { Centralized assessment and report- } \\
\text { ing of replenishment performance } \\
\text { Availability of historical sales } \\
\text { information } \\
\text { Increased replenishment reporting }\end{array}$ \\
\hline $\begin{array}{l}\text { Transfor- } \\
\text { mational }\end{array}$ & $\begin{array}{l}\text { Centralized responsibility of order } \\
\text { planning/forecasting } \\
\text { More integrated planning } \\
\text { More planning flexibility and stan- } \\
\text { dardization }\end{array}$ & $\begin{array}{l}\text { Centralized assessment and report- } \\
\text { ing of replenishment performance } \\
\text { Centralized and automatic order } \\
\text { generation }\end{array}$ \\
\hline
\end{tabular}

Findings of the pharmacy supply chain case show that:

- ICT primarily affected CPFR by enhancing information flows and by enabling process transformation. Compared to its informational and transformational impact, ICT had a less important impact in terms of automation i.e. the use of ICT for substituting labour.

- ICT enabled major enhancements of information flows that contributed to improved planning and control and especially major inventory reductions. Automatic processing and exchange of information was a key aspect for acheiving this outcome.

- ICT enabled major process transformations that were primarily related to the implementation of a common planning and control approach. 


\section{Discussion}

This study revealed that the contribution of ICT in CPFR is primarily related to enhanced information used in planning and control and to the use of ICT in automatic processing and exchange of information. The automatic features of ICT also seem critical to ensure the execution of decisions that are agreed to and a high speed exchange and use of large amounts of information.

It also revealed that ICT contributes to organizational transformation related to the establishment of the joint planning and control approach, especially in order planning/forecasting and order generation. ICT also seems to enable that agreed routines and rules are formalized between partners, promoting collaborative actions. The dependency between ICT and process re-engineering points to that ICT is critical for implementing the CPFR model and for framing a joint planning and control approach.

In view of current literature, this research shows that ICT has further implications in CPFR besides increased efficiency. Findings suggest that ICT has major contributions related to enhancing information and transforming processes and organizations, adding to current CPFR literature, which emphasizes the efficiency perspective of ICT (e.g. Smith, 2006). This study confirms that ICT enhances information, including for instance in terms of scalability and level of detail (Ireland \& Crum, 2005), and that large volumes of information is critical for realizing benefits of ICT (Barratt, 2004a).

A few new aspects, which are not discussed in literature, have also been identified in this research. First, the automatic features of ICT for information processing and exchange have major importance for achieving enhanced information flows. Second, it points to that ICT also has considerable implications in a planning and control perspective, not only for improving information but also for implementing a joint planning and control approach.

\section{Conclusion}

In this study we have explored how ICT affects planning and control processes in CPFR. ICT, such as the APS system of the case study, is expected to improve the performance and success of managing supply chain operations. As an instrument, ICT will lead to benefits such as increased efficiency, supply chain integration and communication, service levels and enhanced speed of information flows. We have showed how the impact of ICT in planning and control processes in CPFR can be related to automational, informational and transformational effects. The main impact of ICT is associated with enhanced information flows and transformed processes.

In an automational perspective, planning and control activities have become less manual, more formalized and centralized. Resources have been allocated to a joint and centralized planning and control team for replenishment decision making. Results related to informational changes show that ICT has contributed to a more efficient planning and control process regarding time and resources. The planning and control instrument has become more precise and real time and demand oriented. ICT has also led to significant transformational changes. The planning and control processes have 
been integrated, redefined and restructured in line with a new and more demand driven joint planning and control approach. A vital element in the new planning and control approach is the real time information and processing capacity enabled by ICT.

This research adds to current CPFR literature by providing insights to the contribution of ICT with focus on enhanced information and process transformation. The importance of automatic features of ICT in information processing and exchange and its contribution to improved planning and control information as well as to implementing a joint CPFR approach, is especially highlighted.

\section{References}

1. Barratt, M.: Understanding the meaning of collaboration in the supply chain. Supply Chain Management 9, 30-42 (2004a)

2. Barratt, M.: Unveiling Enablers and Inhibitors of Collaborative Planning. International Journal of Logistics Management 15, 73-90 (2004b)

3. Cederlund, J.P., Kohli, R., Sherer, S.A., Yao, Y.: How Motorola put CPFR into action. Supply Chain Management Review 10, 28-35 (2007)

4. ECR Europe 2001. A guide to CPFR implementation (2001)

5. ECR Europe 2002. European CPFR: Insights (2002)

6. Ireland, R., Crum, C.: Supply chain collaboration. J. Ross, Boca Raton (2005)

7. Mentzer, J.T., Dewitt, W., Keebler, J.S., Min, S., Nix, N.W., Smith, C.D., Zacharia, Z.G.: Defining supply chain management. Journal of Business Logistics 22, 1-25 (2001)

8. Mooney, J.G., Gurbaxani, V., Kraemer, K.L.: A process oriented framework for assessing the business value of information technology. The DATA BASE for Advances in Information Systems 27, 68-81 (1996)

9. Olhager, J., Selldin, E.: Supply chain management survey of Swedish manufacturing firms. International Journal of Production Economics 89, 353-361 (2004)

10. Seifert, D.: Collaborative planning, forecasting, and replenishment: how to create a supply chain advantage. AMACOM, New York (2003)

11. Skjøtt-Larsen, T.K., Thernoe, C., Andresen, C.: Supply chain collaboration: Theoretical perspectives and empirical evidence. International Journal of Physical Distribution \& Logistics Management 33, 531-549 (2003)

12. Smith, L.: West marine: a CPFR success story. Supply Chain Management Review 10(2), 29-36 (2006)

13. Stadtler, H., Kilger, C. (eds.): Supply Chain Management and Advanced Planning. Springer, Berlin (2008)

14. Vollmann, T.E., Berry, W.L., Whybark, D.C., Jacobs, F.R.: Manufacturing planning and control for supply chain management. McGrawHill, Singapore (2005)

15. Voluntary Interindustry Commerce Solutions Association (VICS), Global Commerce Initiative Recommended Guidelines: Collaborative planning, forecasting and replenishment, CPFR, version 2.0 (2002),

http: / /www.vics.org/docs/committees/cpfr/

CPFR_Tabs_061802.pdf (accessed January 20, 2009)

16. Voluntary Interindustry Commerce Solutions Association (VICS), Collaborative planning, forecasting and replenishment, CPFR (2004),

http: / /www.vics.org/committees / cpfr/CPFR_Overview_US-A4.pdf (accessed January 29, 2009) 